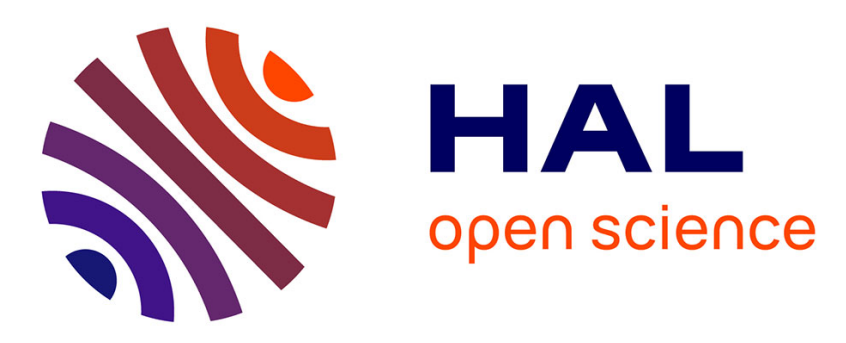

\title{
Electrophysiological evidence for audio-visuo-lingual speech integration
}

\author{
Coriandre Emmanuel Vilain, Avril Treille, Marc Sato
}

\section{To cite this version:}

Coriandre Emmanuel Vilain, Avril Treille, Marc Sato. Electrophysiological evidence for audio-visuolingual speech integration. IMRF 2015 - 16th International Multisensory Research Forum, Jun 2015, Pise, Italy. hal-01297678

\section{HAL Id: hal-01297678 \\ https://hal.science/hal-01297678}

Submitted on 5 Apr 2016

HAL is a multi-disciplinary open access archive for the deposit and dissemination of scientific research documents, whether they are published or not. The documents may come from teaching and research institutions in France or abroad, or from public or private research centers.
L'archive ouverte pluridisciplinaire HAL, est destinée au dépôt et à la diffusion de documents scientifiques de niveau recherche, publiés ou non, émanant des établissements d'enseignement et de recherche français ou étrangers, des laboratoires publics ou privés. 
Audio-visual speech perception is a special case of multisensory processing that interfaces with the linguistic system. One important issue is whether cross-modal interactions only depend on well-known auditory and visuo-facial modalities or, rather, might also be triggered by other sensory sources less common in speech communication. The present EEG study aimed at investigating cross-modal interactions not only between auditory, visuo-facial and audio-visuo-facial syllables but also between auditory, visuo-lingual and audio-visuo-lingual syllables.

\section{Participants}

18 healthy adults, right-handed native French speakers.

* Stimuli

- /pa/, /ta/ and /ka/ syllables were individually recorded by one male and one female speakers in a sound-proof room. Two /pa/, /
and /ka/ tokens were selected per speaker.

- Synchronous recordings of auditory, visua and ultrasound lingual signals were acquired by a Terason T3000 ultrasound system
(UltraSpeech system, Hueber et al. 2008).

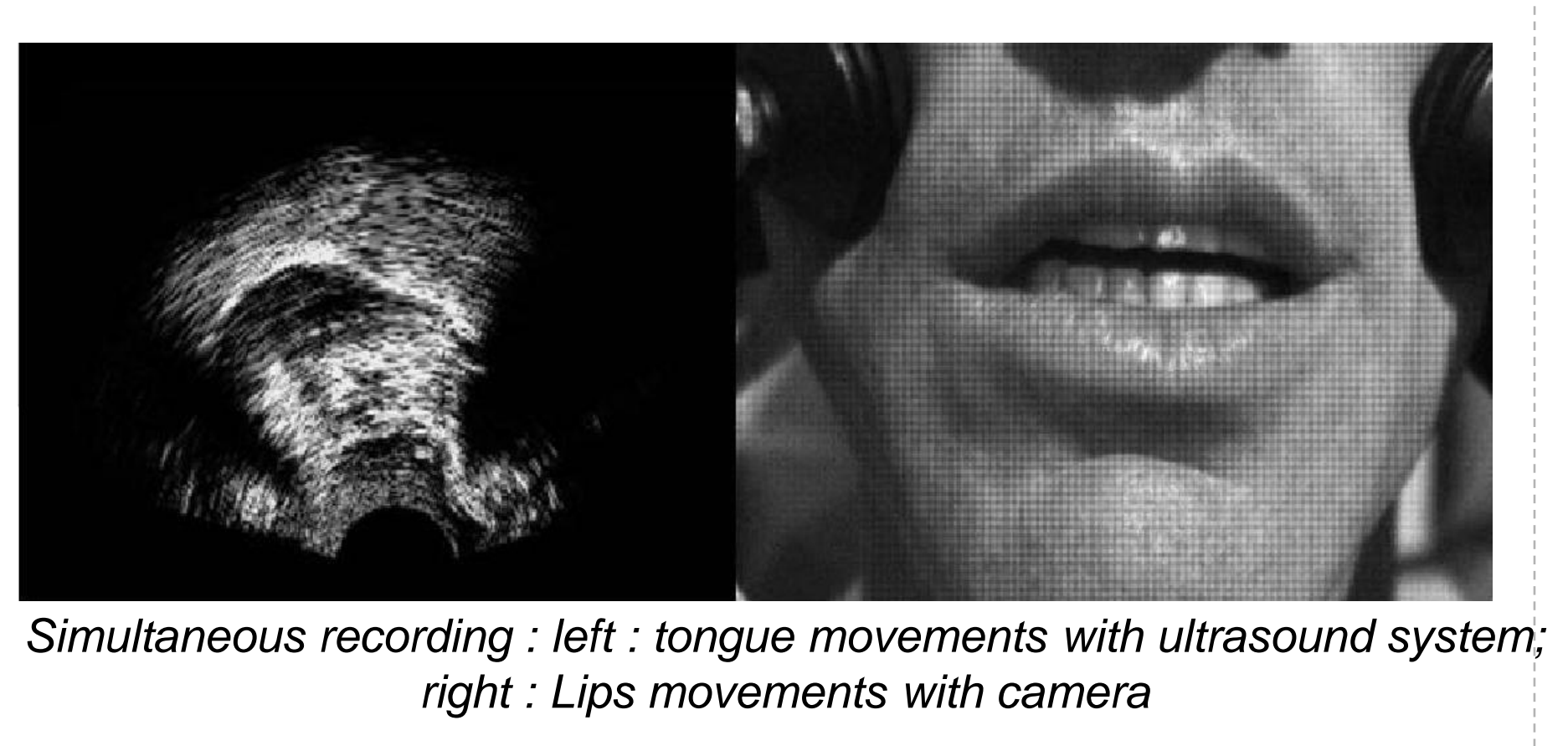

- 60 stimuli were created consisting of $12 / \mathrm{pa} /$, /ta/ and $/ \mathrm{ka} /$ syllables related to 5 conditions: an auditory condition (A), 2 visual (VL, VT) and 2 audio-visual (AVL, AVT) conditions related to either lip or tongue movements of a speaker.

\section{* Method}

1) Before the experiment, short explanations on the ultrasound system and tongue movements required for the production of $/ \mathbf{p a} /, / \mathbf{t a} /$ and $/ \mathbf{k a} /$ syllables were given.

2) Behavioral session: a three-alternative forced-choice identification task, with participants instructed to categorize as quickly as possible each perceived syllable with their right hand.

3) EEG session: a three-alternative forced-choice identification task, with participants instructed to categorize each perceived syllable with their right hand, after an audio "beep".

\section{- Data acquisition}

- EEG data were continuously recorded from 64 scalp electrodes (international 10-20 system) using the Biosemi ActiveTwo AD-box EEG system operating at a sampling rate of $256 \mathrm{~Hz}$.

- Two additional electrodes served as reference [CMS] \& [DRL]

- One other external reference electrode was at the top of the nose. The electrooculogram controlling for horizontal (HEOG) and vertical (VEOG) eye movements were recorded using electrodes at the outer canthus of each eye as well as above and below the right eye. Before the experiment, the impedance of each electrode was adjusted to get low offset voltage and stable DC.

* Analysis

- Behavioral analyses (1):

\begin{tabular}{|c|l|l|}
\cline { 2 - 3 } \multicolumn{1}{c|}{} & \multicolumn{1}{|c|}{ Behavioral experiment } & \multicolumn{1}{c|}{ EEG experiment } \\
\hline$\%$ & $\begin{array}{l}\text { ANOVA : Environment (Noise/No Noise), Articulator } \\
\text { (Lips/Tongue), Modality (A, AV, V) }\end{array}$ & $\begin{array}{l}\text { ANOVA : Environment (Noise/No Noise), Articulator } \\
\text { (Lips/Tongue), Modality (A, AV, V) }\end{array}$ \\
\hline RT'S & $\begin{array}{l}\text { ANOVA : Environment ( (Noise//No Noise), Articulator } \\
\text { (Lips/Tongue), Modality (A, AV, V) }\end{array}$ & \\
\hline
\end{tabular}

- EEG analyses on fronto-central electrodes (F3/F4/C3/C4/Fz/Cz):

\begin{tabular}{|lll|}
\hline $\begin{array}{l}\text { Pre- } \\
\text { processing }\end{array}$ & $\begin{array}{l}\text { - Re-referenced off-line to the nose } \\
\text { - Epochs : } 1000 \mathrm{~ms} \text { (baseline from }-500 \text { to }-400 \mathrm{~ms}\end{array}$ & $\begin{array}{l}\text { - Filtering : } 1-30 \mathrm{~Hz} \\
\text { to the acoustic syllable onset) }\end{array}$ \\
\hline
\end{tabular}

$\rightarrow$ 1) $\mathrm{N1}$ and P2 latency and amplitude analysis by ANOVA with Environment (Noise/No noise), Articulator (Lips/Tongue) and Modality (A, AV) as intra-subject variable (main effects and interactions)

$\rightarrow$ 2) N a
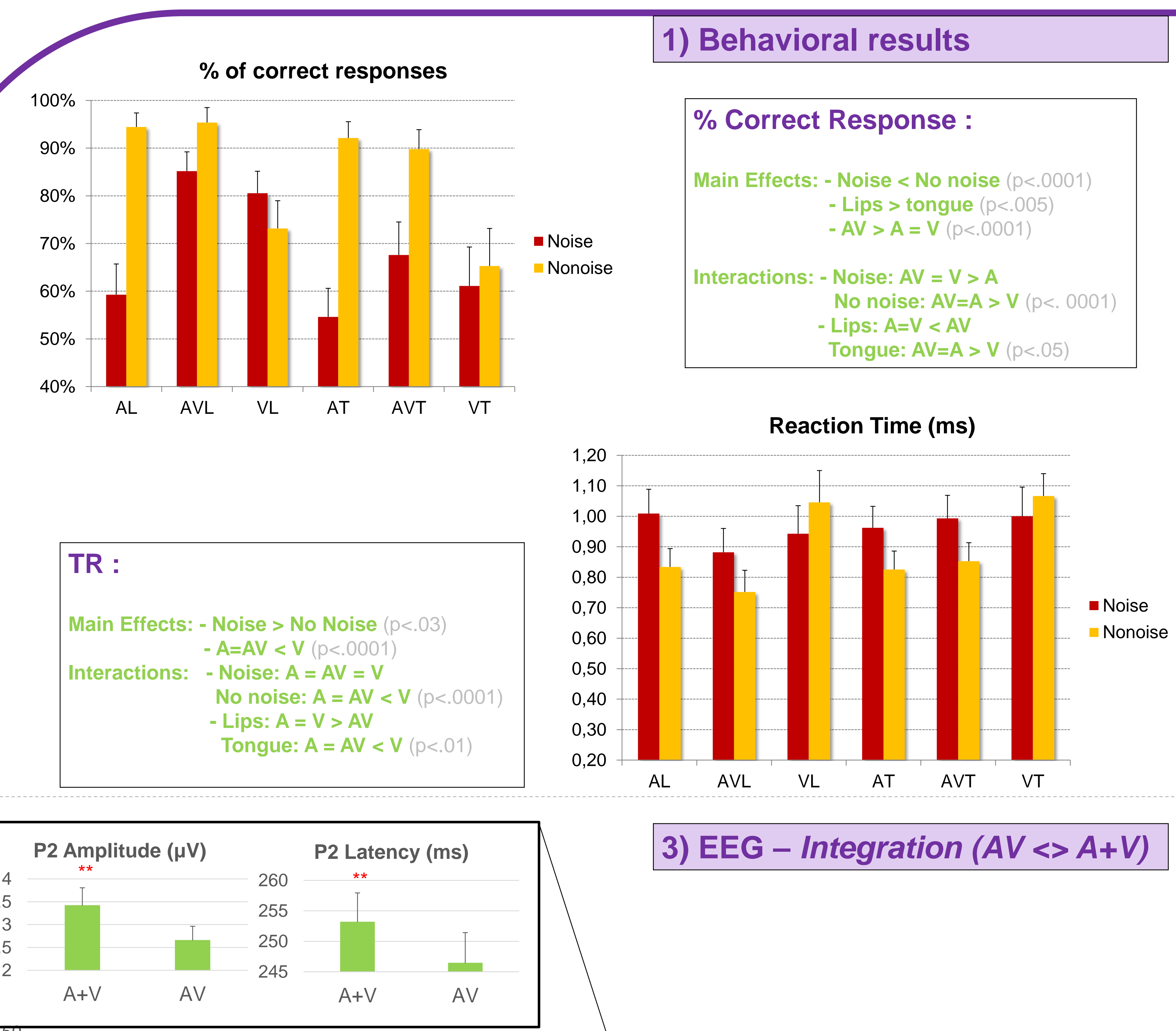

3) $\mathrm{EEG}$ - Integration (AV $<>A+V)$
2) EEG - Noise vs No Noise

N1/P2 - average (AL, AT, AVL, AVT)

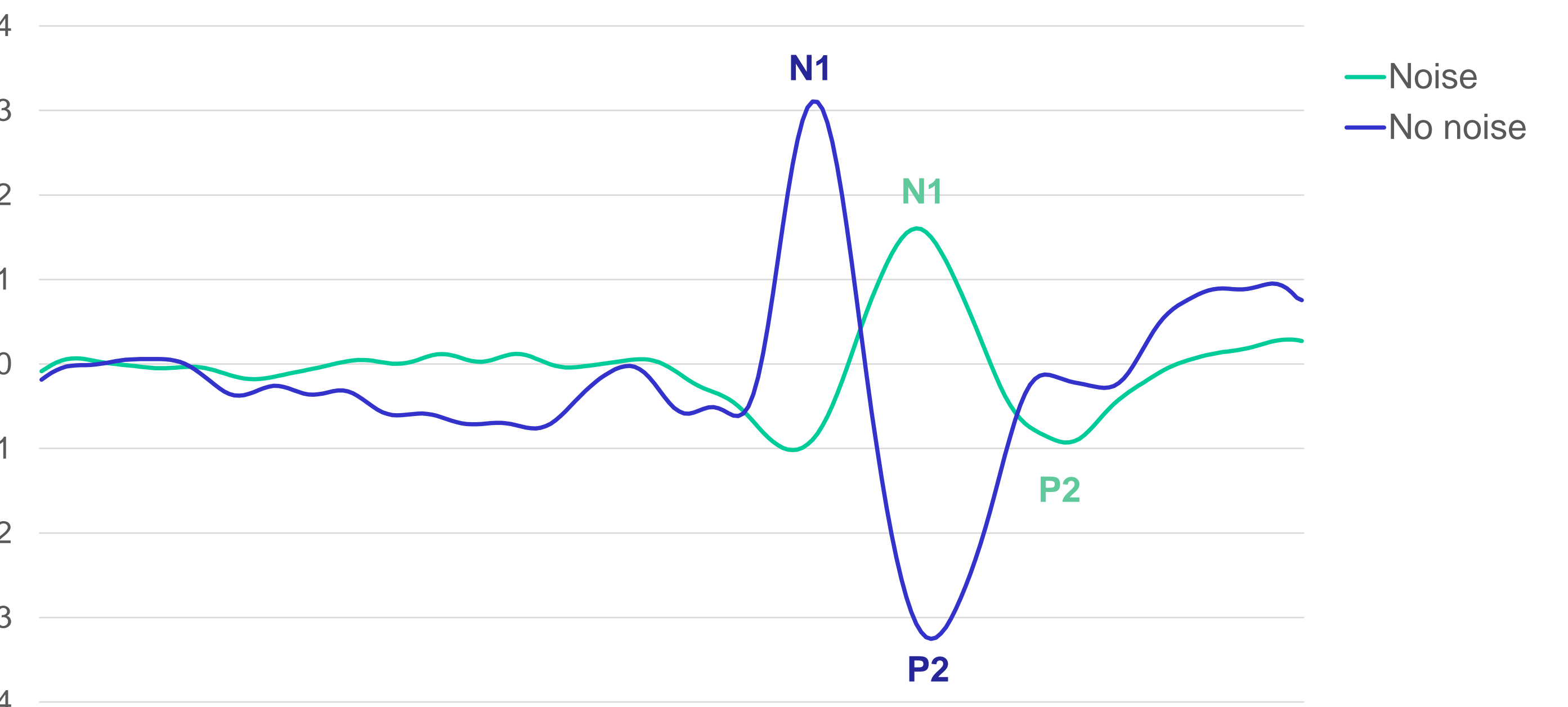

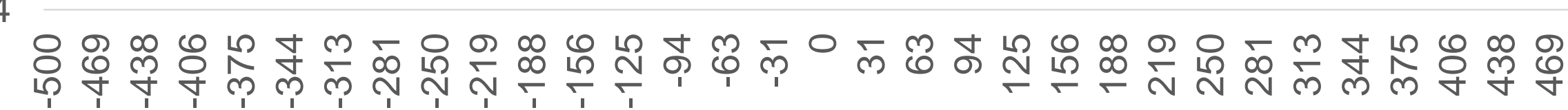

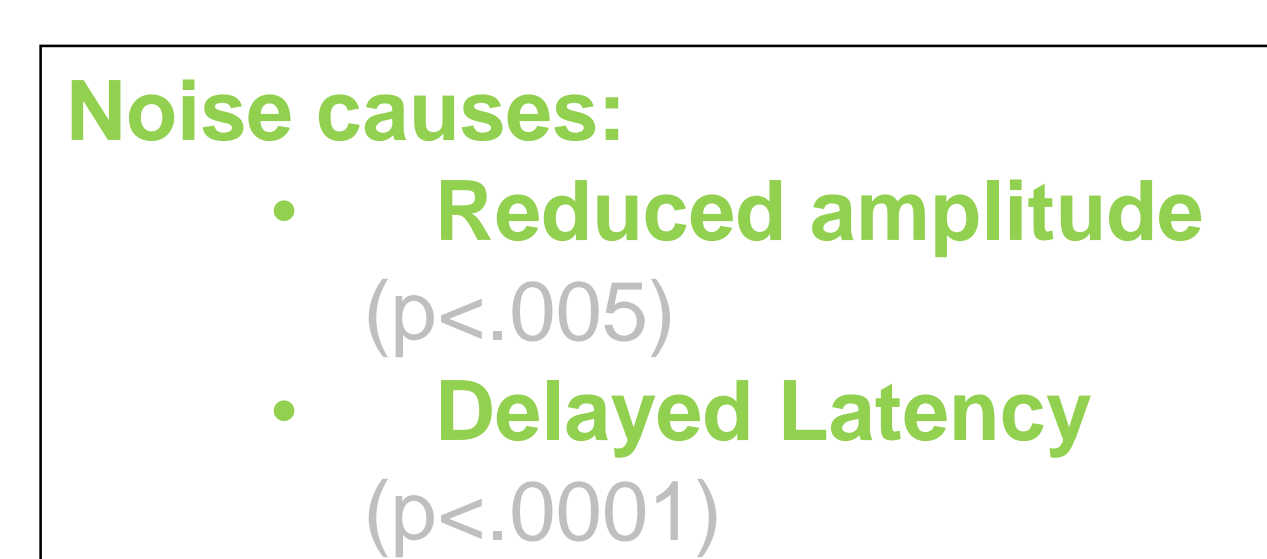

4) EEG - Lips vs Tongue

N1/P2 - average (AL, AVL, AT, AVT in noise and no noise conditions)

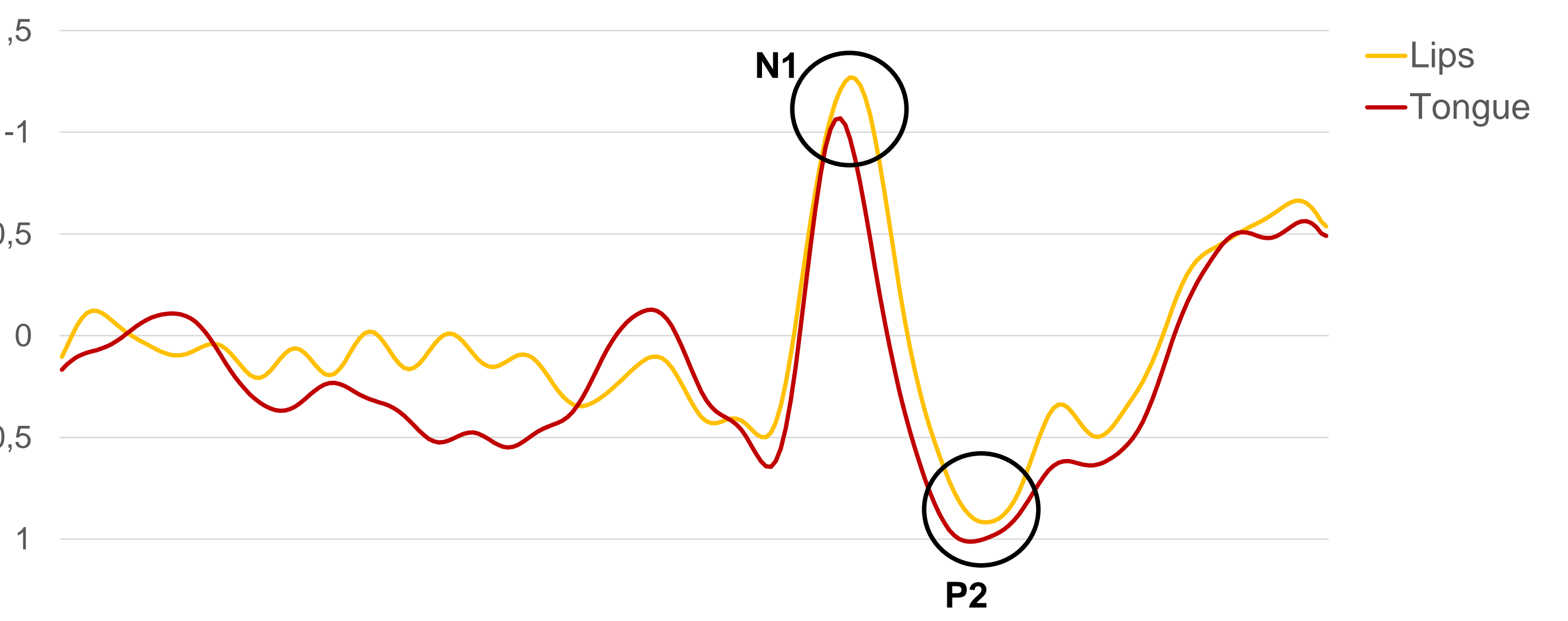

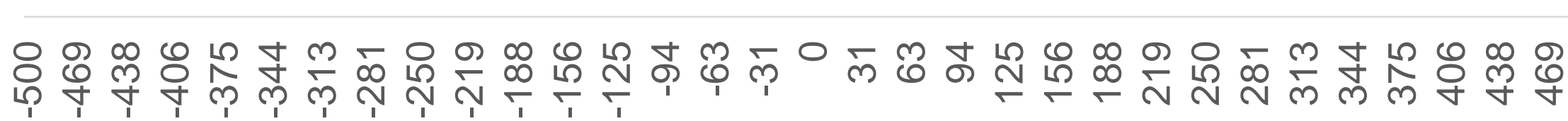
in AV compared to $A+V$ for both lip and tongue signals

For tongue (compared to lips)

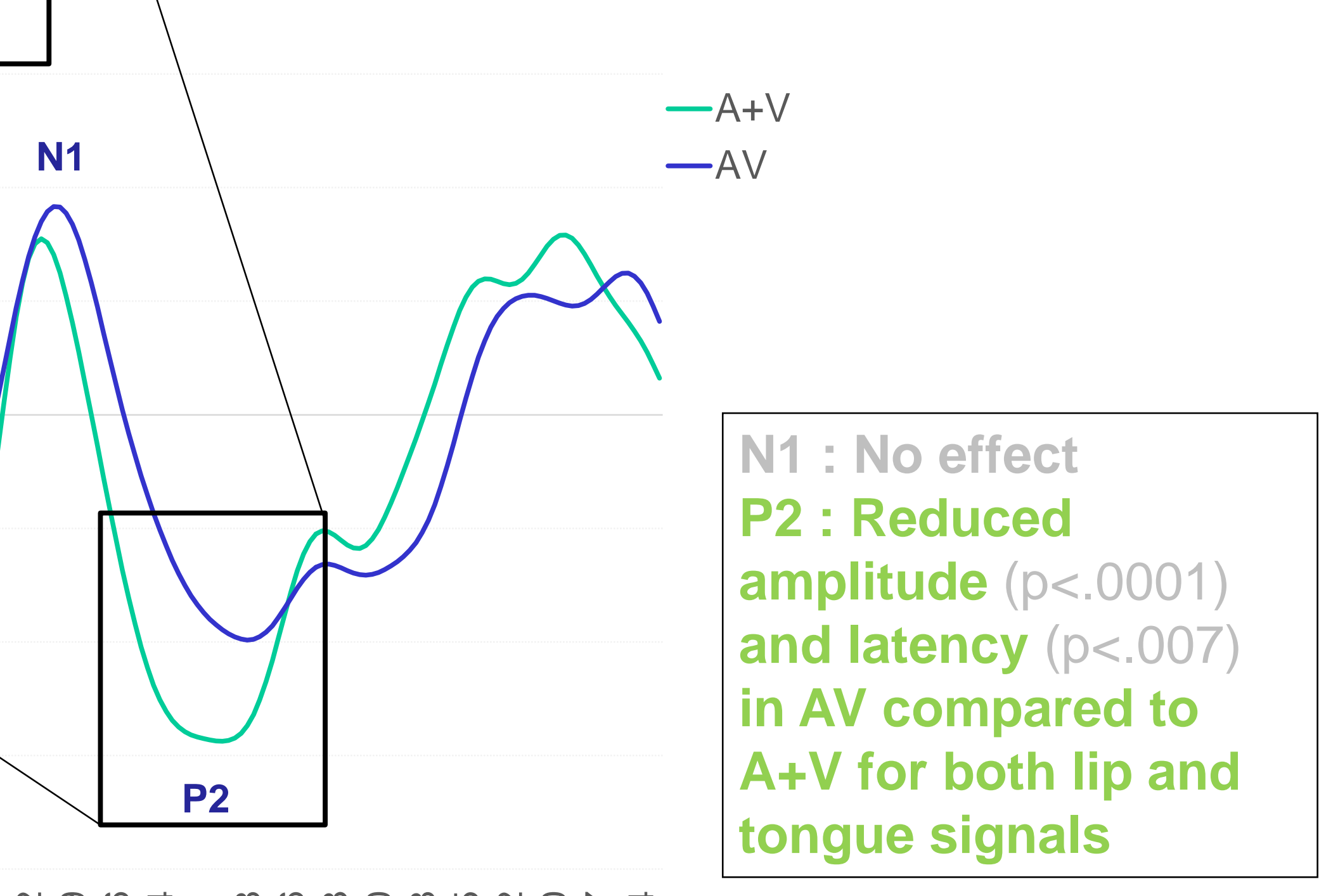
Reduced N1 amplitude

Larger P2 amplitude

Discussion

1) Lips > tongue > chance : For the visual-only modality, syllables are perceived correctly even when they refer to tongue movement.

2) Noise vs No Noise : In line with previous studies, adding noise reduces and shifts the N1/P2 peaks.

3) Integration : Early integration processing (on P2) during AV-lips and AVT-tongue speech perception compared to A+V.

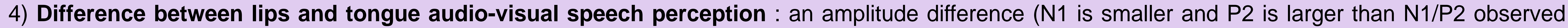
during AV-lips perception)

=> Although participants were not experienced with visuo-lingual stimuli, our results demonstrate that they were able to recognize them and provide the first evidence for audio-visuo-lingual speech interactions. These results further emphasize the multimodal nature of speech perception and likely reflect the impact of listener's knowledge of speech production on speech perception. 